\title{
A Philosophical Appraisal of the Concept of Common Origin and the Question of Racism
}

\author{
Moses Oludare Aderibigbe \\ General Studies Department, School of Sciences, Federal University of Technology, Akure, Nigeria \\ Email: mosesaderibigbe@yahoo.com
}

Received 6 November 2014; accepted 22 November 2014; published 16 January 2015

Copyright (C) 2015 by author and Scientific Research Publishing Inc.

This work is licensed under the Creative Commons Attribution International License (CC BY). http://creativecommons.org/licenses/by/4.0/

cC) (i) Open Access

\begin{abstract}
The quest for a definite answer to some certain ageless philosophical questions such as: What is man? What is his origin? What is his destiny? How is he like other beings in the universe, and how does he differ from them? These have up-till date; remain fundamental questions, which are begging for answers in all human societies. In spite of several attempts from the religious, scientific, cultural and sociological theories to explain the issue of common origin, the problem of racism with all its contradictions persists. This paper is to critically evaluate on one hand, the concept of common human origin, using the various theories to analyse the basis for its justification; on the other hand, examine the issues relating to racism, with the aim of arguing that the meaningfulness or meaninglessness of the universe must start from our understanding of human person and his existence. The philosophical method of conceptual clarification and critical analysis are employed to establish the view that man is the key to the understanding of the whole of reality. Thus, whatever disrespect human dignity regardless of colour, race or sex is to be absolutely rejected.
\end{abstract}

\section{Keywords}

Human, Universe, Racism, Existence, Origin

\section{Introduction}

The aim of this paper is to examine the concept of common origin of human persons in relation to the question of racism in the society. The paper attempts to clarify the two dominant theories that explain common origin which are monogenesis and polygenesis. Just as the former posits a common descent for all human races, the later asserts that different human races descended from different ancestral roots. Following this, the paper proceeds to analyze the ideology of racism which was invented on the belief that human races were not just different from one another, but that some were superior to others. 
However, attempt is made to examine the views of some philosophers, who in the past time postulated about racial differences. Their argument seems to lack moral respect for mankind and deny the rule of equality from the universal point of view. To this end, the paper concludes that since rationality is central to all mankind, the question of racism then becomes untenable.

\section{The Concept of Common Origin}

There are two dominant theories that explain the concept of common origin; these are monogenesis and polygenesis. Monogenesis is the theory of human origin which posits a common descent for all human races. It adhered, on the one hand, to the biblical creation story in asserting that all humans descended from a common ancestor, perhaps Adam and this belief in all human descendants of Adam is central to traditional Judaism, Christianity and Islam (Stephens, 2000). On the other hand, it considers human evolution from a single ape, following Darwin who convinced the scientific community, that humans had a single ancestral origin (Eloise, 1994). This common origin to Darwin is essential for evolutionary theory and thus known as the single-origin hypothesis.

The traditional Christian preference for monogenism is established on two grounds. For some Christians, the defense of the thesis is based directly on certain passages of the scripture. In the Catholic tradition, however, much more emphasis has been placed on monogenism as the only view consistent with the doctrine of Original Sin (Kenneth, 2011). There are passages in both the Old and the New Testaments that suggest a monogenetic origin for the human race. The story of Genesis 2 - 4 depicts the record of the first two human beings. In the same view, Paul's sermon to the Athenians (Acts 17: 26) further establish monogenetic claim of common origin; "from one man”, "one blood" and "one stock”. However, Catholic theology, in its traditional support of monogenesis maintains a consistent view with the doctrine of Original Sin.

Pope Pius XII in his encyclical Humani Generis wrote:

For the Christian faithful cannot maintain the thesis which holds that either after Adam there existed on this earth true men who did not take their origin through natural generation from him as from the first parent of all, or that "Adam" signifies a number of first parents. Now it is in no way apparent how such an opinion can be reconciled with that which the sources of revealed truth and the documents of the magisterium of the church proceeds from a sin actually committed by an individual Adam and which, through generation is passed on to all and is in everyone as his own (Kenneth, 2011).

The above reveals the account of the origin of human race and explains the state of Original Sin which afflicts each human being from his first moment of existence. However, natural science speak more precisely on genetics which leads to the conclusion that although man probably came into being at "one place", the size of that place is only probably a relatively small place and could be as large as the entire old world, the population size might be relatively small but surely not a single couple (Kenneth, 2011). It seems, therefore, unlikely on the basis of scientific evidence that there was a single first couple which emerged alone from a biologically prehuman population to become the ancestors of all human beings. Neo-Darwinism also lends support in favor of polygenism.

However, polygenesis is a theory of human origins positing that the human race are of different lineages, in other words different races of human beings had evolved from different apes. Polygenists reject the argument that human races must belong to a single species because they can interbreed (Jackson \& Weidman, 2005). Polygenism describes all alternative explanations for the origin of humankind that involved more than two individual "first people". Following this, there are three main argument posed against the biblical account of common origin, these include; Pre-Adamism, Co-Adamism and incompleteness of the Table of Nations in Genesis 10 (Livingstone, 1992).

Pre-Adamism claims that there were already races of man living before the creation of Adam. This position was strongly rejected in Christian terms and considered heretical. Co-Adamism argues that there was more than one Adam or small groups of men, created at the same time in different places across the earth, and therefore that the different races were separately created. The Garden of Eden to them is believed to be more than one. The contention of this polygenist on the Table of Nations is that many of the races on earth, such as Negros and Asians were not featured in Genesis 10 and that the author's knowledge was limited to their own region, hence, to them the Bible does not concern the whole of earth's population. Given the above, polygenesis was criticized in the $20^{\text {th }}$ century Roman Catholic Church by Pope Pius XII, on the grounds that it is incompatible with the 
doctrine of Original Sin as quoted in the above passage.

By way of summary, the theories of monogenesis and polygenesis discussed above has made scholars to view these two concept as a mixture of biblical and scientific thought in ways that made scriptural exegesis a scientific activity. Also, it has device a two modes of knowing, one based on the data of revelation favoring monogenesis and the other on the data of observation favoring a polygenetic account of human origin.

\section{Racism}

A precise definition of racism is a bit controversial because there is a little scholarly agreement about the meaning of the concept race. Some scholars argue that the term is applied differentially, with a focus on such prejudices by whites and defining mere observations of racial differences as racism. However, racism is usually defined as views, practices and actions reflecting the belief that humanity is divided into distinct biological groups called races and that members of a certain race share certain attributes which make that group as a whole less desirable, inferior or superior (Newman, 2012).

Similarly, racism is seen as the theory or idea that there is a causal link between inherited physical traits and certain traits of personality, intellect or culture and combined with it, the notion that some races are inherently superior to others (Benton, 1980). In this regard, racism has to do with unfair treatment of people and violence against people that belong to a different race other than your own; also it is the belief that different race of people have different character and abilities and that the qualities of your own race are the best (Longman Dictionary of Contemporary English, 1995).

Tracing the beginning of racism, according to Moore, it is not mere coincidence that racism was invented during the time that tens of thousands of Africans were being captured, enslaved, and transported in chains to the Americas to work as field's hands and manual workers for European owners. It is interesting and important to note that the institution of chattel slavery, in which human beings were considered as mere property, was put into place before scientific racism was invented (Moore, 2008). The point here is that racism is a recent invention, with its assertions about inherent human inequality, whereas slavery was a very old institution in the Mediterranean region of the old world. Following Moore's view, therefore, blackness in ancient times was not equated with the status of slaves, citing the example of Rome where prominent black men, like Emperor Septimius Severus, Consul Lusius Quietus, and a Roman general who became Saint Maurice, the patron saint of medieval chivalry. The only invisible, inherent differences among men which led some to be kings and others to be slaves, according to Plato is the only supposed inequalities among men, which Author Stephen Chorover called "the most frightening document in European history" (Moore, 2008).

Following the above, there is the need to examine the views of some early philosophers, who have contributed in one way or the other to the issue related to racism in the society. This would enable us to secure a good base for a thorough appraisal.

\section{Arguments on Racism and the Concept of Common Origin}

Having defined racism and the concept of common origin, attempt is made here to critically examine some arguments that form the basis for racism. Voltaire in his 1734 book Traite de metaphysique wrote that "Whites... Negros... the yellow races are not descended from the same man". In his later work, he further found biblical monogenism laughable as he expressed:

It is a serious question among them whether the Africans are descended from monkeys or whether the monkeys come from them. Our wise men have said that man was created in the image of God. Now here is a lovely image of the Define Maker: a flat and black nose with little or hardly any intelligence. A time will doubtless come when these animals will know how to cultivate the land well, beautify their houses and gardens, and know the paths of the stars: one needs time for everything (Voltaire, 1769).

Further to the above view, Voltaire, while comparing Caucasians to Negro claimed that they are of different species:

The Negro race is a species of men different from ours as the breed of spaniels is from that of greyhounds. The mucous membrane, or network, which nature has spread between the muscles and the skin, is white in us and black or copper-colored in them (Voltaire, 1733). 
The argument of Voltaire against the black race is quite derogatory to humanity. His idea on polygenesis as a theory of human origin led to his hasty conclusion about the black race, which is highly inhuman.

David Hume, in the same vein exhibited his contempt and aversion for the black race. He placed his argument on the premise that a person's intellectual ability or otherwise is a function of his or her nativity or racial descent. Hume held that the African is incapable of logical thinking and is therefore intellectually unproductive among other inadequacies. Hume believes strongly in the idea that Europe is the model for humanity, culture and history itself. It is this notion of his that led him to conclude that:

I am apt to suspect the Negroes to be naturally inferior to the whites. There scarcely ever was a civilized notion of that complexion; or even any individual eminent in action or speculation (Guido et al., 2003).

From the above, it is clear that Hume attaches great importance to complexion and accords it a prominent role in the determination of a person's rationality or irrationality. It may not be a mistake to conclude that Hume is a racist and racial prejudice has greatly influenced his philosophical insight.

Moreover, Immanuel Kant in his early work, shares the same thought with Hume and ascribed rationality to skin color (white and black) he avers:

"This fellow was quite black from head to foot, a clear proof that what he said was stupid" (Popkin, 1999).

Kant here was not making an empirical hypothesis as Hume had, but was offering a "transcendental" basis for the distinction between whites and blacks. And in so doing Kant established a racial dichotomy between the whites and other people of different skin color. He went further to divide the human race into four groups. First race Northern Europe, second race-copper red (America), third race Black (Senegambia), fourth race, Olive yellow-Indians. To this end, Kant falls into the same racial prejudice and narrow-mindedness which characterized Hume's writing and exposes their lack of genuine philosophical attitude of open-minded and objective way of seeing things beyond self.

Hegel in contradiction to Aristotle stated that of all races; only the Caucasian race (white Europeans and the descendants) have this inherent capability for rationality. According to Hegel the African, Indians and other races lacked the capability for rationality. Thus, they cannot be classified as human; at best they are to be treated as sub-humans.

The summary of the views of these philosophers whose work though might have brought enlightenment to understanding nature, yet is racially sentimental to describe some set of people as incapable of reasoning, primitive, just because they are of different race or origin. Thus, there is no moral, rational and logical justification for such derogatory conclusion or thinking. If for instance, one may ask; to what extent can this claim be true since the race which Hegel excludes from the class of rational beings has been part of the great civilization and center of learning since time immemorial, looking at example of a place like Egypt. By implication, Hume appeared to have committed fallacy of ignorance.

\section{Philosophical Appraisal}

Philosophical discussions on the concept of race are divided into three schools of thought, following the disagreement on the possible ontological status of different conception of race. According to Mallon, there are three metaphysical camps, these are: racial skepticism, racial constructivism, and racial population naturalism (Mallon, 2006), these are in conjunction with two other normative camps (eliminative and conservationism). Racial skepticism holds that because racial naturalism is false, races of any type do not exist. Thus they contend that the term race cannot refer to anything in this world since biological races have been proven not to exist. Prominent in this school of thought are Anthony Appiah and Naomi Zach who adopt normative racial eliminativism, which recommends discarding the concept of race entirely because of its historical genealogy and logical incoherence.

Racial constructivism refers to the argument that, even if biological race is false, races have come into existence and continue to exist through "human culture and human decisions". Race constructivists accept the skeptics' dismissal of biological race but argue that the term still meaningfully refers to the widespread grouping of individuals into certain categories by society, indeed often by the very members of such racial ascriptions. The third school of thought regarding the ontology of race is racial population naturalism. This camp suggest that, although racial naturalism falsely attributed cultural, mental, and physical characters to discrete racial groups, it 
is possible that genetically significant biological groupings could exist that would merit the term races. Importantly, these biological racial groupings would not be essentialist or discrete: there is no set of genetic or other biological traits that all and only all members of a racial group share that would then provide a natural biological boundary between racial groups. Thus, these thinkers confirm the strong scientific consensus that discrete, essentialist races do not exist.

Given the above, the views of each school of thought have its own merits and demerits, and by implication, there is none of them that are absolutely error free. It is against this background that the question of morality becomes relevant in line with the issue of racism as a subject of discussion. Lawrence Blum in addressing the moral status of the concept of race and the problem of racism argues that "racism" be restricted to two referents: inferiorization or the denigration of a group due to its putative biological inferiority; and antipathy, or the "bigotry, hostility and hatred" towards another group defined by its putatively inherited physical traits (Blum, 2002). The point here is that, it should be noted that racism in the light of morality deserves condemnation; this is because it violates moral norms of respect, equality and dignity and also it is historically connected to extreme and overt forms of racial oppression.

Still on the moral status of racism, Angelo Corlett observes that most people agree that racism is a bad thing; however, it is important to understand why racism is morally wrong. A consequentialist would argue that racism is wrong because it brings a balance of economic, social, political and moral evil over good in the world. A deontologist, on the other hand, would argue that racism is to be rejected in that it does not treat humans as ends in themselves, but rather as mere means to the end. Thus, racism disrespects the dignity of humans qua humans, regardless of their respective ethnicities (Corlett, 1998).

The historical connection between racism and extreme oppression from time immemorial has made some scholars to argue against using the term race to distinguish certain group of people from the other. Blum is one of those who advocates using the term "racialized group" instead of the term "race" to denote those socially constructed identities whose supposedly inherited common physical fruits are used to impose social, political and economic costs. To Blum, "racialized group" creates distance from the biological conception of race and it admits other individual according to their racialized identities.

Anthony Appiah in his own metaphysical racial skepticism appear to maintain normative position of eliminativisms, he is "against races" but for "racial identities" (Appiah, 1996). He maintained that there is a wide social consensus that race exists; individuals are ascribed to races regardless of their individual choices or desires. This being the case, racial identity remains far more salient and costly than ethnic identity, thus mobilization along racial lines is justifiable, in order to combat racism. But even at this point, Appiah still fears that racial identification may constrain individual autonomy by requiring members of racial group to behave according to certain cultural norms or "scripts". Hence, he concludes, "racial identity can be the basis of resistance to racism; but even as we struggle against racism... let us not let our racial identities subject us to new tyrannies".

The metaphysical view presented by Appiah in this context is observed by some critics that Appiah remains an eliminativist rather than a racial constructivist. He prefer to be free of all residual constraints entailed by socially constructed races, he is therefore not a radical critique of race. The point to note here is that the position maintained by Appiah is to buttress further the idea that race or racism should better be perceived from the sense of being a mark of identities which should not constrain individual autonomy. To this end, the extent to which this can be realized without constrain is the concern of his critique.

On this note, the arguments of the racialist philosophers as pointed out earlier appears untenable, it lack moral respect for mankind and denies the rule of equality and as well dehumanize human race from the universal point of view. To this end, central at the heart of humanism are two key ideas. First, humanists hold that human beings, while an inherent part of nature and subject to its laws, nevertheless have an exceptional status in nature because of the unique ability arising out of human rationality and sociability to overcome the constraints placed upon them by nature. Second, humanists believe in the unity of humankind, holding that all humans possess something in common, a something that is often described as a common "human nature".

Following these two key ideas, the concept of common origin invariably can be established on the premise of human rationality and common human nature. Thus, the question of superiority or inferiority which racism brought to the fore cannot hold, so far beyond all reasonable doubt it has been universally established that common to all men, in respective of the skin color is found rationality and common human nature as manifests in flesh and blood. The point here is that, the singular fact that all human persons are rational is enough a logical reason to establish the claim that all men have common features. What differentiate them is not more of internal 
(nature), rather it tends towards other factors that are external.

\section{Conclusion}

This paper sets out to clarify basic concept of common origin. In doing this, an effort was made to define the two dominant theories which are monogenesis and polygenesis. The question of racism which is central to this paper was discussed and the views of philosophers who could be termed as racist was analyzed. The three main schools of thought in philosophy of race were brought to the fore with a critical view from the morality of the whole issue. The conclusion hinged on the fact that most arguments raised in favor of racism, lack moral respect for mankind and negate the common feature possess by mankind which is rationality.

\section{References}

Appiah, A. (1996). Race, Culture, Identity: Misunderstood Connections. In A. Appiah, \& A. Gutmann (Eds.), Color Conscious (pp. 80-81). Princeton, NJ: Princeton University Press.

Benton, W. (1980). Encyclopedia Britannica (Vol. 15). London, 258.

Blum, L. (2002). I'm Not a Racist, But... The Moral Quandary of Race Ithaca. New York: Cornell University Press.

Guido, B. et al. (2003). Dictionary of Race, Ethnicity and Culture. London: Sage Publications, 242.

Corlett, A. (1998). Analyzing Racism. Public Affairs Quarterly, 12, 23-50.

Eloise H. M. (1994). Race and Ethnicity: An Anthropological Perspective Jean Ait Belkhir. Race, Gender \& Class Journal, 1, 138.

Jackson, J. P., \& Weidman, N. M. (2005). Race, Racism, and Science: Social Impact and Interaction. New Jersey: Rutgers University Press.

Kenneth, W. K. (2011). Science, Theology, and Monogenesis. American Catholic Philosophical Quarterly, 85, 218.

Stephens, L. D. (2000). Science, Race and Religion in the American South. John Bachman and the Charleston Circle of Naturalist (1815-1895). 293.

Livingstone, D. (1992) The Preadamite Theory and the Marriage of Science and Religion. Transaction of the American Philosophical Society, New Series, 82, 63.

Longman Dictionary of Contemporary English (1995). New Edition. Pearson Educational Limited Essex.

Mallon, R. (2006). Race: Normative, Not Metaphysical or Semantic. Ethics, 116, 515-525. http://dx.doi.org/10.1086/500495

Moore, J. H. (2008). Encyclopedia of Race and Racism (Vol. 2). New York: Macmillan Reference.

Newman, D. M. (2012). Sociology Exploring the Architecture of Everyday Life (9th ed.). Los Angeles: SAGE, 405.

Popkin, R. (1999). The Columbia History of Western Philosophy. New York: Columbia University Press, 513.

Voltaire (1733). The Works of Voltaire (Vol. xix). Philosophical Letters.

Voltaire (1769). Les Lettres d' Ameb. Septieme Lettre d’ Ameb. 
Scientific Research Publishing (SCIRP) is one of the largest Open Access journal publishers. It is currently publishing more than 200 open access, online, peer-reviewed journals covering a wide range of academic disciplines. SCIRP serves the worldwide academic communities and contributes to the progress and application of science with its publication.

Other selected journals from SCIRP are listed as below. Submit your manuscript to us via either submit@scirp.org or Online Submission Portal.
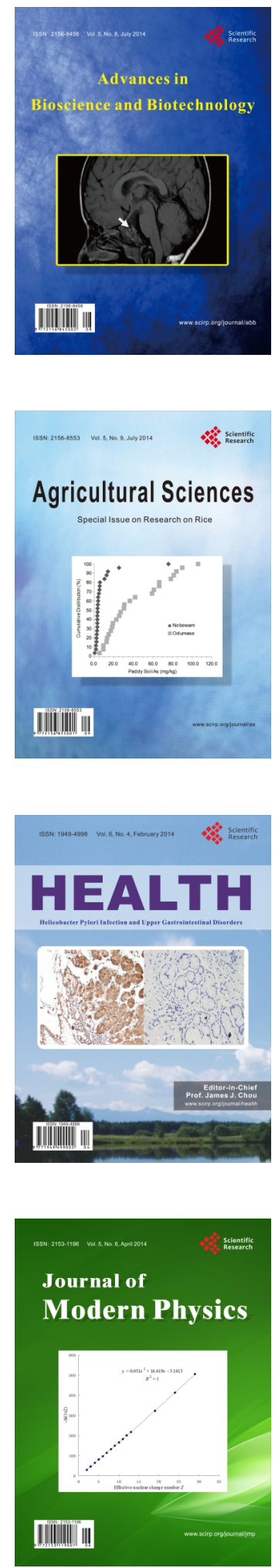
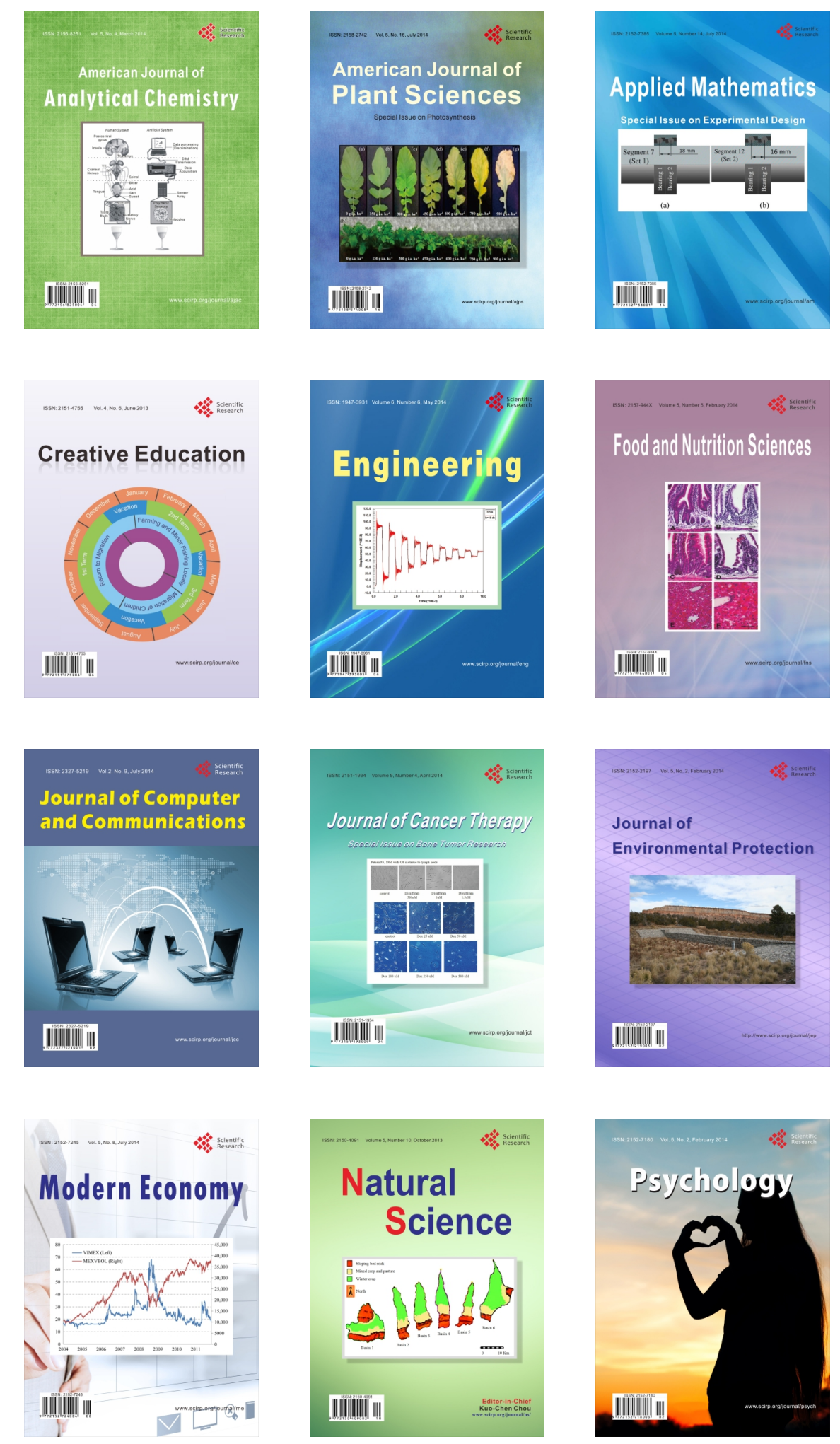